\title{
Gestão participativa de recursos hídricos na bacia do Córrego da \\ Prata: inclusão social e desenvolvimento no Alto Vale do \\ Jequitinhonha, Minas Gerais
}

\author{
Ricardo Rodrigues Félix dos Reis ${ }^{1}$ \\ Cláudio Márcio Pereira ${ }^{1}$ \\ Carlos Henrique de Oliveira ${ }^{2}$ \\ Daniel Ferreira da Silva ${ }^{1}$ \\ Helton Nobuyuki Hizuca ${ }^{1}$ \\ Sula Janaína de Oliveira Fernandes ${ }^{1}$ \\ Lariane Chaves Junker ${ }^{1}$
}

\begin{abstract}
${ }^{1}$ Universidade Federal dos Vales do Jequitinhonha e Mucuri - UFVJM
Rua da Glória,189 - 39100-000 - Diamantina - MG, Brasil.

ricardo_freis@yahoo.com.br,souzacmp@yahoo.com,danielufvjm@yahoo.com.br,

nobuhizuca@yahoo.com.br,sulafernandes@hotmail.com,larianejunker@gmail.com
\end{abstract}

\author{
${ }^{2}$ Empresa de Assistência Técnica e Extensão Rural - EMATER - MG \\ Rua do Tijuco, 186 - 39100-000 - Diamantina - MG, Brasil. \\ carlos.henrique@emater.mg.gov.br
}

\begin{abstract}
This study sought to develop alternatives to the increasing environmental degradation in the "Córrego da Prata", located on River Basin Jequitinhonha, which is currently threatened by urban sprawl. The goal is to raise community associations Peri urban areas with a view to training water managers committed with the recovery of the stream, both with regard to water quality, the ecosystem of the basin, along with participatory environmental monitoring of water resources in the Upper Vale Jequitinhonha.
\end{abstract}

Palavras-chave: water managers, Upper Vale Jequitinhonha, Córrego da Prata, gestores hídricos, Alto Vale do Jequitinhonha 


\section{1 - Introdução}

A gestão participativa em torno dos recursos hídricos é um aspecto de suma importância no desenvolvimento de uma região, bem como de uma sociedade. A água tem sido o foco principal em muitos debates ao redor do mundo, juntamente com as alterações climáticas, causada pelo aumento desordenado da população, e a falta de consciência com relação ao uso racional dos recursos naturais.

O aumento crescente da população vem ocasionando uma grande transformação no espaço, movida tanto por uma concepção de desenvolvimento já ultrapassada, quanto pelo ensejo de dar concretude às dimensões sócio-ambientais renovadoras. Em ambos os casos, caminham, o cidadão e o meio ambiente em sobressaltos. Atualmente o espaço é o mais escasso dos recursos nacionais, lembra Alva (1997).

Nos últimos anos temos assistido a imposição em todo o mundo, de um modelo de desenvolvimento com a afirmação do modo de vida urbano, todavia esse modelo tem ocasionado graves efeitos negativos no meio ambiente, sendo mais significativos os que atingem os recursos hídricos. A crescente demanda de água para consumo humano e produtivo, sem oferta correspondente, e a degradação dos mananciais, tornaram-se preocupações relevantes, tanto em nível nacional quanto mundial.

O desenvolvimento das regiões interioranas configura pressões sobre o ambiente, mas especificamente sobre a água, as quais são passíveis de se tornar insustentável em médio prazo, pois incita formas de exclusão social e predação ambiental inaceitáveis. À medida que as cidades se desenvolvem, refletir sobre a gestão dos mananciais, significa refletir sobre a própria lógica perversa ou sustentável da configuração das cidades Spöil \& Seabra (1997).No caso de Diamantina não é diferente, o município vem padecendo com a degradação de suas águas, devido à ausência de uma política urbana sustentável.

O município de Diamantina-MG está localizado nas coordenadas geográficas $18^{\circ} 14^{\prime} 58^{\prime}$ 'S e $43^{\circ} 36^{\prime} 01^{\prime}$ 'O, na Região denominada Alto Vale do Jequitinhonha. Cidade conhecida pela sua alma histórica, berço de riquezas, principalmente no que se refere ao diamante, recurso mais explorado durante séculos, e que persiste nos dias de hoje. Diamantina é uma cidade que como qualquer outra convive com problemas ambientais, devido ao crescente aumento da população e a ocupação desordenada. O Córrego da Prata, situado na Bacia Hidrográfica do Rio Jequitinhonha, um dos principais córregos do município, vem sofrendo com o abandono e descaso tanto dos moradores, como dos representantes políticos, sendo o alvo principal do crescimento exacerbado da população. $\mathrm{O}$ lançamento de efluentes domésticos diretamente no córrego, in natura, e a conseqüente diminuição da vazão, tornou o aproveitamento de suas águas impróprio para o abastecimento urbano, persistindo ainda, algumas pessoas que utilizam-se das águas do Prata para consumo doméstico e para atividades do dia-a-dia, como lavação de roupas. 
O município é marcado pela precariedade da habitação de baixa renda e pelo adensamento de moradias em Áreas de Preservação Permanente, onde as características físicas e ambientais são inadequadas à ocupação, tendo solos arenosos, sendo prejudicados ainda mais pela ocupação,devido a sua baixa estabilidade, o que leva prejuízo para o leito do córrego, tornando vulnerável várias espécies e causando riscos à integridade humana. Quanto menor a renda da população, mais escassos os lugares acessíveis a sua moradia contemplados com serviços urbanos (galerias pluviais, iluminação, coleta de lixo, saneamento básico, etc.), os quais acabam sendo aproveitados apenas por aqueles que podem pagar seu preço, incluído na renda do solo que dá acesso à eles Schneider(1998).

Esse trabalho visa mostrar a atual situação do Córrego da Prata, e a importância da Gestão Participativa no que diz respeito à Capacitação de Gestores de Recursos Hídricos, na busca de atores conscientes do seu papel na sociedade quanto a recuperação e preservação dos recursos hídricos e do meio ambiente, no que se refere à qualidade da água e ao ecossistema da bacia, que são de extrema importância para a população e para o município de Diamantina.

\section{2 - Objetivo Geral}

O presente trabalho buscou desenvolver alternativas para a crescente degradação ambiental no Córrego da Prata, localizado na Bacia hidrográfica do Rio Jequitinhonha, que atualmente se encontra ameaçado pelo crescimento urbano desordenado. O objetivo é sensibilizar as associações comunitárias Peri - urbanas com vistas à formação de gestores de recursos hídricos comprometidos com a recuperação do Córrego, tanto no que se refere à qualidade de água, quanto ao ecossistema da bacia, juntamente com o monitoramento ambiental participativo dos recursos hídricos no Alto Vale do Jequitinhonha.

\section{3 - Materiais e Métodos}

Para a realização do projeto, a Universidade Federal dos Vales do Jequitinhonha e Mucuri, apoiada pelo Centro Nacional de Pesquisas, e em parceria com a EMATER-MG e com o Sindicato dos Trabalhadores Rurais de Diamantina, através de seus discentes convidou os professores e diretores de todas as escolas públicas, os presidentes das Associações Comunitárias, e moradores dos bairros banhados pelo Prata.Também foi convidada a empresa responsável pela distribuição de água do Município e professores da Universidade, bem como a população Diamantinense, para participar do curso de Gestão Participativa de Recursos Hídricos na bacia da Prata, sendo o córrego citado o objeto de estudo.

O curso foi ministrado em dois finais de semana, cumprindo-se a carga horária de oito horas estipulada para cada núcleo. Os professores convidados proferiram as palestras pertinentes à cada núcleo, onde foram distribuídas cartilhas 
educativas de cada tema e materiais como pasta, bloco de anotações, caneta, camiseta, , como apoio nas ações de multiplicação dos gestores. Também foi elaborado um questionário, onde a equipe de futuros gestores, levantou informações sobre as condições atuais do Córrego da Prata,através de uma caminhada ecológica realizada ao final do curso.

Os núcleos de estudo ministrados serviram para passar as informações necessárias aos futuros Gestores dos Recursos Hídricos, visando especificamente quatro temas principais:

\section{1 - Núcleo de Educação Ambiental}

O objetivo básico deste núcleo foi sensibilizar os gestores para a importância da utilização sustentável da água e a conservação dos recursos hídricos como imprescindíveis a melhor qualidade de vida em suas comunidades.Foi transmitido aos gestores o valor de um córrego bem protegido, bem como seus benefícios à população.

\section{2 - Núcleo de Proteção de Nascentes e Reflorestamento}

Diagnosticar e a catalogar as nascentes existentes nos arredores do Córrego da Prata juntamente com os gestores ambientais e conhecer a importância da proteção das nascentes e recuperação da mata ciliar.Foram abordadas práticas de reflorestamento e a importância de um estudo prévio a respeito da área e da vegetação que se desejar recuperar.

\section{3 - Núcleo de Saneamento Básico Peri - urbano}

Coube a este núcleo transferir noções básicas sobre saneamento, enfatizando o tratamento de efluentes domésticos (esgoto) e o destino das fezes de currais e pocilgas. O responsável pelo núcleo falou a respeito de compostagem, e maneiras de se minimizar a poluição direta sofrida pelo córrego.

\section{4 - Núcleo de Ecoturismo}

Esse núcleo buscou colaborar para o desenvolvimento sustentável das populações do Córrego da Prata, evidenciando o turismo como alternativa econômica e de inclusão social, além de resgatar e valorizar os patrimônios históricos, culturais, e os recursos paisagísticos, hídricos e naturais que circundam o córrego. Foram realizadas dinâmicas, onde os gestores lembraram do Córrego a alguns anos atrás, comparando com a sua atual situação.

\section{4 - Resultados e Discussão}

Através da caminhada participativa foi possível constatar a variedade de espécies da fauna e flora encontradas na bacia, bem como das 
principais potencialidades da região, os principais pontos de entrada de efluentes domésticos, a atual situação do córrego e tudo o que lhes foi relevante em relação ao ecossistema da bacia e a interação da população com a mesma.

Ao final dos trabalhos houve a proposta da formação de um comitê gestor da Bacia do Córrego da Prata, já que os gestores saíram do curso com uma visão diferenciada a respeito dos seus direitos e deveres como cidadãos, e engajados principalmente como gestores de recursos hídricos, vislumbrando novas possibilidades para a melhoria dos bairros onde vivem, e conseqüentemente da sociedade cercada pela bacia do Córrego da Prata, possibilitados pela gestão participativa.

\section{5 - Considerações Finais}

A capacitação atingiu o objetivo maior que era formar Gestores Hídricos afinados com as políticas ambientais e com as necessidades imediatas do Córrego da Prata, buscando a melhoria da qualidade da água do córrego, conseqüentemente atingindo parte da população necessitada de informações e novas visões a respeito da gestão dos recursos naturais, enfocando principalmente os recursos hídricos.

O projeto buscou a interação entre entidades e comunidade, visando a proteção e comprometimento com uso racional dos recursos hídricos, esse que nos possibilita a sobrevivência durante a nossa jornada nesse planeta, contando para isso com a gestão participativa de toda a população para que esse recurso dure por muito mais tempo e garanta a vida de muitas pessoas durante várias gerações.A nossa preocupação também é evidente, como a de Cabral (MMA,2001 , p. 15) quando indaga:

"Como pode ter problemas um país que tem água? Como nós, brasileiros, a estamos tratando?" Ao que ele mesmo responde: "É muito aflitivo comprovar que a estamos tratando muito mal. A administração dos recursos hídricos é um setor para o qual não podemos adiar ações concretas. (...) A escassez, em algumas áreas do Brasil e do mundo, não nos permite postergar medidas para estabelecer o uso racional dos recursos disponíveis."

\section{6 - Referências}

FELICIDADE, N. MARTINS, R.C. LEME, A.A. A Água como Valor Social: Considerações Acerca de uma Prática Acadêmica em Torno do Tema. In: FELICIDADE, N. MARTINS, R.C. LEME, A.A. (Orgs.). Uso e Gestão dos Recursos Hídricos no Brasil. São Carlos: RiMa,2001.p. 3-15. 
FELICIDADE, N. VARGAS, M.C. MIRANDA, C.O. O Processo de Interiorização do Desenvolvimento e Suas Implicações ao Acesso e Uso da Água pelo Cidadão: Desafios Econômicos, Sociais e Político-Institucionais do Caso Paulista. In: FELICIDADE, N. MARTINS, R.C. LEME, A.A. (Orgs.). Uso e Gestão dos Recursos Hídricos no Brasil. São Carlos: RiMa,2001.p. 223-236.

OLIVEIRA, C.M. de.Instrumentos da Política Nacional de Recursos Hídricos do Brasil.In:ESPÍNDOLA,E.L.G.;SCHALCH,V.(Orgs.). Bacia Hidrográfica: diversas abordagens em pesquisa. São Carlos: RiMa,2004.p. 351-366.

SÁNCHEZ, P.S. BELLO, E.A.D.Ocupação Periférica de Baixa Renda em Áreas de Mananciais.In: FELICIDADE,N.;MARTINS,R.C.;LEME,A.A.(Orgs.). Uso e Gestão dos Recursos Hídricos no Brasil. São Carlos: RiMa,2001.p. 205-222. 